\title{
The Effectiveness of the Blackboard Technique in Integrating Saudi University Students' English-Language Reading and Writing Skills
}

\author{
Mahmoud Abd Al-Naser Nasr*
}

Doi: //10.47015/17.4.12

Received on: 3/3/2020

Accepted on: 2/6/2020

\begin{abstract}
The aim of the current study was to test the effectiveness of the Blackboard technique in integrating English-language reading and writing skills of Saudi university students. The participants of the study consisted of 40 students selected randomly from Qassim University, including both males and females. The one-group experimental design was used. After pretesting, the experimental-group students were taught by using a proposed model implementing a suggested Blackboard-based strategy. The strategy aimed at integrating reading and writing. Then, the posttest was administered. Results indicated that there were statistically significant differences between the mean scores of the students in the pre -and post- administrations of the test in favor of the post-administration. No significant differences were detected between the mean scores of males and females in the experimental group in the post administration of the test.
\end{abstract}

(Keywords: Blackboard Technique, Integration Approach, English-language Skills, Reading and Writing Skills, Teaching Model, Saudi University Students)

\section{Introduction}

Modern technology created a personal space for EFL learners to read and write in their online community. This virtual space can add a "boost of broadness and validity" to the teaching/learning environment (Al-Saghir and Wazen, 2020:17). It enables learners to share their ideas in their social network and to constructively and positively provide feedback on one another's work, which in turn, helps foster intra-team and inter-team interactions with readers and writers (Al-Harbi, 2015: 111). Technology renders it easy for learners to properly manage their learning time by adhering to assignment deadlines, contacting their instructors online for queries and academic consultations with no time restrictions and immediate updates regarding learning and assessment activities, ... etc. (Mohsen and Shafeeq, 2014:108) in a relatively compatible environment that can improve the overall quality of students' outcomes (Evans, 2018:2).

\section{أغالية استخداه تقنية بلاك بورد في دمج مهارتي القراهة

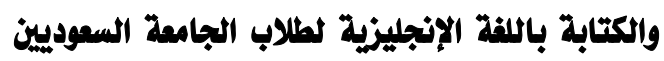

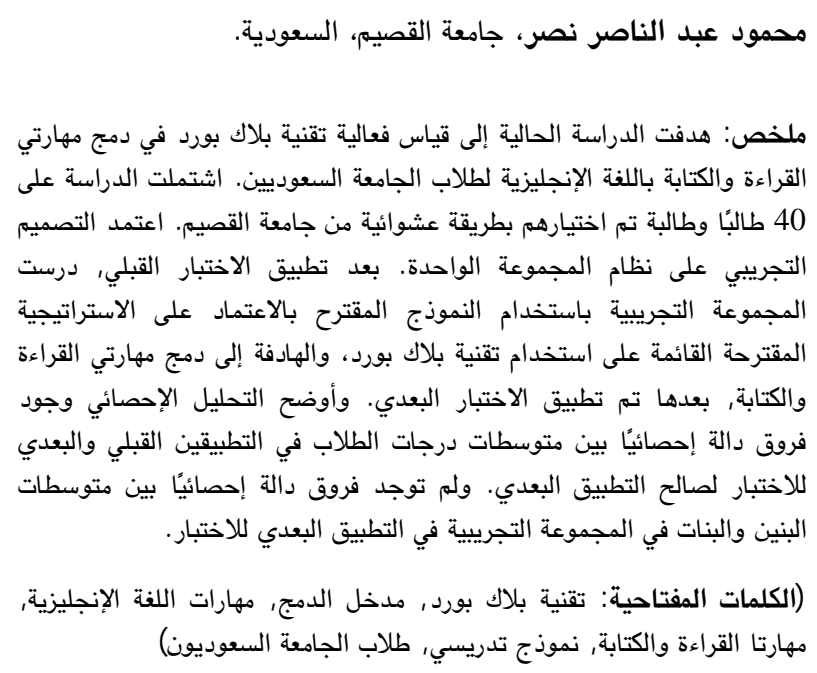

Course management systems (CMSs) are important and promising instructional tools to help teachers manage their courses and enhance student learning outcomes. These functions can be used to assist the storage and distribution of teaching materials, the recording and monitoring of learning schedules and activities and the evaluation of teaching and learning quality. The integration of CMSs with language instruction is promising, because they support metacognitive self-regulation and help provide a suitable motivational level during students' learning processes. CMSs can inspire, motivate and guide students to develop self-regulated learning cognitive skills (Tsai, 2015: 153-171). The widespread availability of technological infrastructure has enhanced the adoption of learning-management systems (LMSs) in educational institutions. 
LMSs, including Blackboard, are considered among the most commonly used and useful types of e-learning systems for both students and instructors in academic institutions. For instructors, LMS provides different online course-management features which allow instructors to post announcements and grades as well as manage quizzes and exams (Tawalbeh, 2018: 1-9). For students, LMS has improved their online communication with the instructors by motivating them to play an active role in the learning process, rather than playing a passive role of receiving information through traditional methods, such as instructors and textbooks (Tella, 2011: 55-80). Bouhnik and Marcus (2006: 299) stated that elearning has four advantages: freedom to decide when each online lesson will be learned, lack of dependence on time constraints of the lecturer, freedom to express thoughts and ask questions without limitations and the accessibility to online materials at students' own election.

Blackboard is a web-based learning tool to post information, documents, assignments and announcements. It may allow real-time activities, such as chat rooms that can be used for student-toinstructor and instructor -to- student document transfer (Tawalbeh, 2018: 1-9). It is one of the most popular marketable LMSs adopted in highereducation institutions, due to its ubiquity, easiness and accessibility. It promotes student-centered learning, which is meant to prioritize students' interests, abilities and learning styles (Mohsen and Shafeeq, 2014:109). Blackboard learningmanagement system includes a set of features and functionalities that help teachers and students communicate effectively in an academic setting and enhance students' learning opportunities (Tawalbeh, 2018: 7). Blackboard-based instruction has been adopted, as it provides numerous opportunities for EFL teachers and learners to meet via online classrooms. Blackboard-based instruction can ensure more equal participation among learners. In other words, whereas face-toface discussions tend to be relatively unbalanced, with one or two participants dominating class discussions, communication in Blackboard-based instruction ensures more balanced participation. Accordingly, Blackboard-based instruction has proved to be effective in improving EFL students' achievement by creating functional virtual communities where relevant, meaningful learning can be generated in dynamic, interactive contexts (El-Ghamry, 2016: 49-67). The tools in
Blackboard have the potential to change the way teachers teach and learners learn. They offer a highly interactive medium of learning that can be customized to meet the individual needs of students (Mohsen and Shafeeq, 2014:108-118). One of such needs, for sure, is developing Englishlanguage skills.

The current research trends have consistently demonstrated that reading and writing skills should be presented and learnt in tandem. This integration can engender a symbiosis where EFL learners can learn to write by reading and learn to read by writing (McArthur, 2014). Integration becomes a key component of the classroom. Accumulated literature on reading/writing instruction argues for a paradigm shift toward a reading-writing integration in composition classes (Al-Dosari and Mekheimer, 2013: 61-81). Integration between reading and writing helps immerse students in the target language through which they gain knowledge of the target-language culture and norms. By integrating reading and writing, teachers are able to move away from pedagogies which are heavily based on discrete items of knowledge and assessment, such as grammar translation, and move towards a more constructivist style of instruction, whereby students construct their own knowledge based on class materials (Al-Malki and Soomro, 2017: 93-102). Learning primary receptive and productive skills in integration reinforces each other and maximizes effectiveness of studying language. Integrated-skills approach enables the use of real language, establishes social interaction, enhances group and pair work and contributes to the greater language retention. Integrating skills can also enable students to show their communication competence relying on a written or an oral text. It can ensure success in academic or professional communication and everyday interaction (Pysarchyk and Yamshynska, 2015: 7783).

Empirically, ardent research efforts have been strenuously exerted to investigate the relative effectiveness of Blackboard in developing Englishlanguage skills. It is most legible in this juncture to cast light on some of such attempts. Mohsen and Shafeeq (2014) investigated teachers' perceptions on Blackboard applications in the context of EFL. 32 university teachers from Saudi Arabia were surveyed and interviewed. Results revealed that EFL teachers had positive perceptions on Blackboard applications. Most teachers viewed 
Blackboard as a structured e-learning platform that helps improve the teacher-student relationship and aids to make teaching English more successful.

Al-Harbi (2015) explored the effects of online-course tools, specifically discussion boards, blogs and wikis and built-in facilities of Blackboard on improving integrated reading and writing and on the attitudes of EFL college students. 60 participants were enrolled in a 16week academic writing-4 course in King Khalid University in Saudi Arabia. Findings indicated that the students' performance on an integrated reading/writing test was improved and so were their attitudes. The e-course tools at issue facilitated students' interactions and supported learning of the reading/writing skills in a growing online-course community. Tsai (2015) designed a teaching model that utilized Blackboard to support English-writing instruction. 247 students participated in this study. Results of two academic years were analyzed in a quasi-experimental study. Results showed that the experimental group significantly outperformed the control group in final drafts. Most students displayed positive learning outcomes.

El-Ghamry (2016) investigated the effect of Blackboard on pre-service teachers' achievement in the teaching-methods course at the Faculty of Education at Bisha, K.S.A. 40 students were randomly assigned into the experimental and control groups. The experimental group received instruction via Blackboard Collaborate, whereas the control group received traditional instruction. The two groups were pre-post tested. Results revealed that Blackboard-based instruction was effective in enhancing the achievement of the experimental group. El-Feky and Masadeh (2016) examined the effect of mobile learning on the development of the achievement and conversational skills of English-language students at Najran University. Participants consisted of 50 students divided into experimental and control groups. The course was uploaded to the university Blackboard for students in the experimental group. A hardcopy of the course was delivered to students in the control group. Results showed that mobile learning had quite significant effects on students' achievement and conversational skills. Al-Turki; Al-Draiweesh and Athabaska (2016) investigated accessibility and usability of Blackboard. The elements that were evaluated included the design user interface, navigational features, and ease of use. The researchers targeted 400 faculty members from different colleges, consisting of three categories: health colleges, humanities colleges and science colleges in King Saud University. Results proved the hypothesis that Blackboard is accessible and usable by the teachers from different faculties for the delivery of content.

Ali (2017) identified non-English major university students' perceptions of Blackboard. Blackboard software was used to deliver Basic English-grammar course for non-English major university students in Qassim University, K.S.A. 50 students in the English-language course responded to a questionnaire uploaded through Blackboard. Students were asked to use discussion boards, do assignments, see announcements, answer quizzes and identify course documents posted by the instructor. Results showed that most of the students felt that using Blackboard was useful and enjoyable. Al-Hassan and Shukri (2017) investigated the effect of utilizing Blackboard on enhancing EFL female students' satisfaction in the Saudi context. The sample consisted of 98 students. A questionnaire was used to identify students' level of satisfaction. Results revealed that students' satisfaction was apparent, as their positive responses outweighed their negative responses in terms of richness of learning resources, opportunity to interact in foreign language, appropriateness of content and ease of using Blackboard.

Tawalbeh (2018) investigated EFL instructors' perceptions of Blackboard at Taif University, K.S.A. A questionnaire was used to gather data from 102 instructors. Results revealed that $75 \%$ of the instructors have not used Blackboard technology before coming to university. Most of the instructors believed that the different features of Blackboard are either poor or very poor. The instructors rarely or never used the system. Moreover, the results revealed that the instructors had a positive attitude towards the system.

Al-Saghir and Wazen (2020) investigated the compatibility of e-learning platforms with a competency-based educative (CBE) approach as an integrative framework. For comparison purposes, the compatibility of three other learningmanagement systems; namely, Blackboard, Canvas and Brightspace, with the CBE approach was also examined. Comparison showed that the explored elearning platforms offered a relatively compatible 
environment to the elaborated framework for online courses.

\section{Problem of the Study}

During the last few years, the researcher got to use the Blackboard technique only as a supplementary aid in teaching. It served well in sending announcements, recording lectures, giving exams and quizzes, ... etc. However, during the hard times of Corona virus, nothing was available to use, but Blackboard. It became the sole medium to reach the students. As formal teaching in real classrooms was suspended, Blackboard loomed large as a feasible aid to finish courses, collect assignments, administer exams and quizzes; in short, every teaching/learning detail went through Blackboard. Via the researcher's ample experience in using Blackboard, he got to know abreast that it has various potentialities which teachers as well as students can make use of. Hence, the current study attempted in the first instance to investigate the effectiveness of Blackboard in developing integrated English-language skills. The problem in perspective arose also from the noticeable low level of Saudi university students in integrated English-language skills. Such a dire case is the net outcome of a bevy of factors among which is the weak emphasis such skills receive in teaching practices all over educational stages. Using methods and strategies which are not in accord with the nature of such skills aggravates the situation. Teaching such skills separately does not allow the students to realize the inherent relationship between them which, if discovered and nourished properly, would enhance such skills synchronously. Such skills have, in fact, mutual interdependence; that's, development in one of them may lead directly to similar development in another. Research stresses the practical relationship between reading and writing. A large number of studies suggest that teaching writing skills through reading is a more effective mode of instruction than merely focusing on exclusive teaching of such skills. However, the status quo is so far away from such an optimistic approach to teaching. One of the reasons for the low level of such skills among Saudi students is the lack of emphasis on readingwriting connection in the language classroom. Each skill is dealt with in a separate class using a separate textbook used by a separate teacher via a separate teaching method and aid only to be tested by a separate test. Methodologies of teaching such skills, in most cases, are at odd with the nature of such skills. Reading classes change into loudreading exercises. Writing classes get to emphasize the quantity of writing regardless of writing techniques and aesthetics. Between the two realms lies a gulf of incongruities.

This state gave the researcher momentum to probe deeply into the effectiveness of using Blackboard in developing integrated Englishlanguage skills of Saudi university students. The researcher was propelled to conduct the current study via the following:

1-The researcher's long experience in the field of English-language teaching (for more than 25 years) illustrated that integrated Englishlanguage skills do not get due attention. The researcher felt that there is a dire need for more research to find new innovative strategies using modern technologies that are apt to develop such skills and to bring them into focus. The opportunity offered itself when Blackboard became the only available formal means of teaching during the time of Corona virus.

2-A thorough review of pertinent literature in perspective revealed that there is a noticeable paucity in research conducted to develop integrated English-language skills of QassimUniversity students via Blackboard.

3-Recommendations of other researchers in the field (e.g. El-Feky and Masadeh (2016); AlMalki and Soomro (2017); Al-Hassan and Shukri (2017); Tawalbeh (2018); Wong (2018); Chen et al. (2019); Al-Saghir and Wazen (2020), among others) the plethora of which lay emphasis on the significance of using learning-management systems (LMSs), especially Blackboard, recommend that more studies should be conducted to devise new strategies in order to develop integrated English-language skills.

4-The researcher's reaction against segregatedskills instruction so prevalent in Englishlanguage teaching. Several research studies have indicated that Saudi EFL teachers focus less on reading-writing connection in their instruction.

5-Most of the studies investigating the use of modern technology in education in K.S.A have concentrated on the theoretical perspective. Such studies have emphasized views of teachers and students regarding the application of modern technology in education. Thus, more empirical studies are needed in this juncture. 


\section{Objectives of the Study}

The present study aimed at fulfilling a twofold objective:

1.An instructional objective: Proposing a teaching model using Blackboard in order to develop integrated English-language skills of Qassim-University students.

2.A research objective: Testing the effectiveness of the suggested Blackboard-based model in developing integrated English-language skills of Qassim-University students, as well as investigating the difference between males and females in integrated English-language skills as per the effect of using Blackboard.

\section{Questions of the Study}

The present study attempted to find answers to the following questions:-

1. Is there a significant difference between the mean scores of the experimental-group students in the pre-and post-administrations of the integrated English-language skills test?

2. To what extent is the proposed Blackboardbased model effective in developing integrated English-language skills of Saudi university students?

3. Is there a difference between males and females in integrated English-language skills as per the effect of using Blackboard?

\section{Significance of the Study}

Suspending formal classrooms during the time of Corona virus made Blackboard a single choice for the majority of Saudi teachers and students. Henceforth, the significance of the current study emanates from the fact that it may guide teachers, especially those who did not venture into using modern technologies in their teaching, into using Blackboard whether in emergencies or in normal teaching/learning situations. The study may motivate teachers as well as students to deem integrated English-language skills as demanding skills of language that need to be looked after. Moreover, the study proposes a model as well as a strategy using Blackboard with the aim of developing integrated English-language skills of Saudi university students. In addition, the study may help students, teachers and course designers via helping students develop their integrated English-language skills, guiding English teachers by improving their teaching practices of such skills and providing course designers with what's needed to develop these skills. Furthermore, to the best knowledge of the researcher, no study had been conducted to propose and use such a type of teaching model in Saudi Arabia for the stage chosen. As a result, the present study tried to fill in this gap.

\section{Limitations of the Study}

The researcher used the one-group experimental design with a pre-post test. The study was conducted in the province of Qassim, Saudi Arabia, where the researcher lives and works. It was undertaken on 40 students enrolled in level 2, Dep't. of English and Translation. Students were selected randomly out of Qassim University, including both males and females. The experimental study lasted 6 weeks, approximately 3 hours per week. The study was conducted during the second semester of the academic year 2019/2020.

\section{Operational Definitions of Terms} study:

The following terms were used in the present

Blackboard: In this study, the term 'Blackboard' is used to mean a web conferencing system which allows teachers and students to communicate with one another synchronously and asynchronously, view presentations or videos, interact with other participants, and engage with resources in work groups.

Integrated English-Language Skills: For the purpose of the current study, the term refers to an attempt to do without the segregation approach of teaching reading and writing in isolation and to teach them both in unity. The net result will be a bevy of reading/writing sub-skills. Such sub-skills were assessed in the present study using a standardized test prepared by the researcher.

\section{Methods of the Study}

In conducting the current study, the researcher made use of:

1. The Descriptive Method: This method was used for reviewing pertinent literature, determining integrated English-language skills suitable for Saudi university students and identifying the general outline of the proposed model as well as the suggested teaching strategy. 
2. The Quasi-experimental Method: This method was used while conducting the experiment, administering the proposed model and the integrated English-language skills test, analyzing data and interpreting results.

\section{Population and Participants}

The study was undertaken on 40 students selected randomly out of the Faculty of Sciences and Arts, Qassim University, including both males and females.

\section{Instruments of the Study}

\section{I-The Proposed Model}

The major objectives of the proposed model were to develop integrated English-language skills: Reading and writing. The instructional content comprised four units after making the required integration between Effective Academic Writing II. Alice Savage and Patricia Mayor, OUP (2007), and Interaction 2. Reading. Kirn Elaine and Hartman Pamela, McGraw-Hill College (2007). Both are prescribed for level 2, English-language students, Department of English and Translation.

\section{The Proposed Teaching Strategy}

The researcher designed a teaching strategy which went as follows:

(1) The researcher inaugurated the experiment with an intensive and comprehensive introduction - all online - to the students about the integrated English-language skills. The researcher held a brainstorming session a half of which was assigned to reading processes, types, methods of improvement, ... etc. The other half was assigned to basics of writing, skills deemed to be pivotal for writing, difficulties students encounter while attempting writing, ... etc. By the end of the session, the researcher trained students in how to achieve integration between the two skills.

(2) A special online workshop was held in order to raise students' awareness of e-learning and to train them - at least those who were novice users - in using Blackboard. Available potentialities of Blackboard were all elucidated. By the end of the workshop, the researcher made sure that all students were able to use Blackboard in an innovative way. Students were trained in using the following Blackboard icons:
-The first icon to be used was that of "Content". The researcher used it for creating and uploading new files, assignments, videos, images, links, flickers, slides, You-Tubes, media sites, Blackboard open content, ... etc. It served well in preparing quizzes and short tests.

-The second icon was that of "Discussion". The researcher made very good use of it in the mainstream of teaching the content. Online group discussions helped in putting reading and writing skills into practice.

-The third icon used was that of "Groups". Students were divided into small groups for collaborative work and competition at the same time.

-The fourth icon was that of "Tools". A great attention was paid to such an icon, since it encompasses so many operations needed by both the teacher and the students, the first of which is Blackboard collaborate. Tasks, zoom meetings, emails, diaries, evaluations, course directives, course messages, discussion panels, wiki sites, blogs and many others are also included within such an icon.

-The fifth icon was that of "Grading Centre". This enabled the researcher to score and record tests.

-The sixth icon was that of "Instructions". This included common problems, and offered suitable aids.

(3) Teaching procedures of integrated Englishlanguage skills went as follows:

First: A text was selected and presented for reading. Procedures went through three sequential and interrelated stages.

\section{Pre-reading Stage}

This stage included:-

* Clarifying the output of reading the chosen text.

* Getting the main idea of that text.

* Drawing a mind map for the main idea.

\section{During reading Stage}

This stage included:-

* Intensive-reading and scanning skills.

* Deducing the conceptual meaning in the text.

* Building a vocabulary stock. 
* Identifying syntactic and morphological relationships in the text.

* Understanding inferred ideas from the text.

\section{Post-reading Stage}

This stage included:

* Transferring information from one context and using it in another.

* Drawing connections between main ideas using mind maps.

* Reflecting upon the information in the text via writing a summary.

Second: The topic formerly dealt with was presented for writing. Procedures went through three sequential and interrelated stages.

\section{Pre-writing Stage}

This stage included:

* Identifying writing objectives and specifying the target audience.

* Determining a proper expository context, logical scope and sequence and going through a detailed outline within a concise framework.

\section{During-writing Stage}

This stage included:

* Writing the first draft.

This step included:

* Specifying the topic of writing in the thesis statement and its controlling ideas.

* Offering a brief background with sufficient details.

* Reaching final viewpoints and opinions.

\section{Post-writing Stage}

This stage included:

* Editing and revising.

*Checking accuracy, clarity, coherence and cohesion, keeping logical order and maintaining the flow of the ideas, sustaining the readers' attention and maintaining all technicalities of academic writing all through the written text.

\section{Recapitulation Stage}

During this stage, students were usually called for a group forum in order to discuss what has been done during each session. Connections between the skills dealt with in each session were stressed.

\section{Activities Accompanying the Model}

The researcher utilized a crop of online activities, such as brainstorming, concept mapping, using realias, contextualizing language, warm-ups, student projects, controlled-writing practice, freewriting practice, peer correction, teacher/peer feedback, watching English movies, selfreviewing, feedback and feedforward, instant writing, collaborative writing, using online dictionaries, using Gmail and Google search, creating personal accounts, creating personal sites, working in pairs and groups, whole-class discussions, thinking-aloud protocols, think-pairshare, student presentations, problem-based learning, challenge-based learning, inquiry-based learning, jigsaw puzzles, extensive internet surfing, reading online texts to use them as resources for writing assignments, using a reading log, taking notes and records while reading, peer composition and review, $\ldots$ etc.

\section{Methods of Evaluation}

Two types of evaluation were used while conducting the experiment:

a-A pre-test before administering the experiment.

b-A post test after administering the model.

\section{Validating the Model}

The layout of the proposed model was submitted to a panel of specialists in curricula, instruction and applied linguistics to show their opinions. The researcher took the juries' observations into consideration. The researcher made the utmost use of the juries' opinions whenever he found a certain consensus among them upon a certain reading/writing skill. The skills strongly agreed upon were implemented in the model. Juries' suggestions as per the general layout, objectives, activities, ... etc. of the model were all taken into account.

\section{Pilot Administration}

The researcher piloted the suggested model using the proposed strategy prior to the real experiment. The pilot study lasted one week. 12 students participated in this pilot study. 


\section{II-The Integrated English-Language Skills Test}

The test aimed at assessing integrated Englishlanguage skills of Saudi university students. It was employed as a pre-post test in order to determine the effectiveness of the proposed model. The researcher prepared the test in light of the goals, objectives and skills previously specified. The test consisted of 15 questions totaling 6o marks.

\section{Validating the Test}

In order to prove test validity, it was submitted to a jury committee of specialists in curricula, instruction, psychology and applied linguistics to show their opinions. A soft copy of the test was emailed to each jury member with a cover letter forwarding eight items to be judged as being suitable or not. Items pertained to suitability of objectives, question formats, distribution of scores, ... etc. The jury members agreed upon the validity of the test. Thus, content validity was assured. Moreover, the researcher proved self validity of the test which reached 0.94 .

\section{Reliability of the Test}

The test-retest method was used with a time span of 15 days. Reliability coefficient reached 0.89 .

\section{Facility, Difficulty and Discrimination Indices of the Test}

Facility, difficulty and discrimination indices were computed. They were $0.72,0.28$ and 0.20 , respectively.

\section{Pilot Administration of the Test}

The researcher administered the test to a pilot sample of 11 students in order to make sure of the suitability of the test, calculate the mean time needed, compute reliability and diagnose problems that might arise while administering it.

\section{Results of the Study}

In order to answer the first research question, the researcher used t-test as follows:

Table (1)

Terminal Means, Standard Deviations and t-Test Results for the Scores of the Experimental-Group Students in the Pre-and Post-Administrations of the Test

\begin{tabular}{ccccccccc}
\hline Test & Number & Mean & $\begin{array}{c}\text { Standard } \\
\text { Deviation }\end{array}$ & $\begin{array}{c}\text { Difference between } \\
\text { Means }\end{array}$ & \multicolumn{2}{c}{ Free } & Calculated Tabulated & Level of \\
Score & $t$ & t & Significance \\
\hline Pre & 40 & 32.03 & 4.43 & 22.94 & 78 & 14.51 & 1.68 & $\begin{array}{c}\text { Sig. at } 0.05 \\
\text { level }\end{array}$ \\
Post & 40 & 54.97 & 8.86 & & & & &
\end{tabular}

It can be noticed from Table (1) that there are statistically significant differences at 0.05 level between the mean scores of the experimentalgroup students in the pre-and post-administrations of the integrated English-language skills test in favor of the post administrations. For an interpretation of such a result, the researcher attributes this significant difference to the proposed model. The suggested Blackboard-based strategy is the cornerstone in this juncture. The strategy aimed, in the first instance, at developing integrated English-language skills via the use of Blackboard. It gave momentum to all of the learning/teaching situation. It can be said to have empowered the students, reduced teacher's domination, eliminated traditional routine and monotony and given momentum to students' latent potentialities and participation. Students' awareness of the skills to be practiced beforehand may be said to have provided them with opportunities to get ready. Moreover, providing students with the objectives of each lesson in advance may be assumed to have motivated their latent expertise and potentialities. It helped students assess their progress step by step. Feedback had a vital role to play in this respect. Furthermore, the proposed Blackboard-based strategy engaged students in practicing the targeted skills. It brought into use students' schematic knowledge about a certain topic to be tackled. In addition, the classes proceeded in an atmosphere that was similar to a workshop. Instant advice was asked for and offered. Immediate help was provided. On-the-spot feedback was available. Mistakes were discussed publicly to provide some kind of feedback.

In order to answer the second research question and to determine the effectiveness of the proposed model, the researcher used Blake's formula as follows: 
Table (2)

Mean Scores of the Experimental Group in the Pre-and Post-Administrations of the Test, Total Score and the Gain that Occurred

\begin{tabular}{ccccc}
\hline Test & $\mathrm{N}$ & $\mathrm{X}$ & $\begin{array}{c}\text { Total Test } \\
\text { Score }\end{array}$ & Gain \\
\hline Pre & 40 & 32.03 & 60 & 1.20 \\
Post & 40 & 54.97 & & \\
\hline
\end{tabular}

It can be noticed from Table (2) that the ratio of gain lies within the range determined by Blake, which is (1-2). This indicates the effectiveness of the proposed model in rendering its target. The effectiveness of the proposed model may be attributed to a bevy of factors: First, adopting a scientific method in designing it; second, identifying integrated English-language skills needed by Saudi university students beforehand; third, presenting the objectives of each lesson to the students before starting it; fourth, enriching the model with various activities; fifth, using various teaching techniques subsumed beneath the suggested Blackboard-based strategy; sixth, using different kinds of teaching aids; seventh, using various kinds of evaluation before, during and after the experiment. Furthermore, types of interaction among the students and between the students and the researcher may be said to have given momentum to students' latent potentialities. All through administering the experiment, the researcher got to detect that the Blackboard-based strategy augmented positive interdependence among students whenever they got involved in group processing. This encouraged speed up learning, increased collaboration efficiency, supported information sharing and enhanced selfexpression. For sure, students' taking lead of the learning/teaching situation gave them vent that enhanced their performance. Results of the current study are commensurate with those reached by ElGhamry (2016); Al-Turki et al. (2016); Ali (2017); Hamad (2017); Evans (2018); Cooney, Darcy and Casey (2018); Niyibizi, Sibomana and Perumal (2019); Chen et al. (2019) and Al-Saghir and Wazen (2020).

In order to answer the third research question, the researcher used t-test as follows:

Table (3)

Terminal Means, Standard Deviations and t-Test Results for the Scores of Males and Females in the Experimental Group in the Post-Administration of the Test

\begin{tabular}{ccccccccc}
\hline Gender & Number & Mean & $\begin{array}{c}\text { Standard } \\
\text { Deviation }\end{array}$ & $\begin{array}{c}\text { Difference between } \\
\text { Means }\end{array}$ & $\begin{array}{c}\text { Free } \\
\text { Score }\end{array}$ & C. t & T. t & $\begin{array}{c}\text { Level of } \\
\text { Significance }\end{array}$ \\
\hline Males & 20 & 53.88 & 8.18 & 0.42 & 38 & 0.15 & 1.72 & Insignificant. \\
Females & 20 & 54.3 & 8.98 & & 38 &
\end{tabular}

It is obvious from Table (3) that there are no statistically significant differences between the mean scores of males and females in the experimental group in the post-administration of the test. The result in perspective may illustrate that difference in gender did not render difference in integrated English-language skills. Inherent and latent complexities, potentialities and cognitive processes of such skills may be said to depend primarily on the coordination of other cognitive, psychological, technical, psychomotor and methodological variables that may not be largely affected by difference in gender. Since information processing and cognitive processes may be similar in males and females, such skills may be affected by other factors rather than difference in gender. This finding is in congruence with that reached by Nasr (2019) who found out that there was no significant difference in writing between males and females. Aliweh (2011) also found out that students' gender had no bearing on their satisfaction with web-based materials (In AlZumor et al., 2013).There is still paucity in research in this area. Therefore, the researcher seizes the opportunity to call other researchers to further investigate such a controversial topic.

\section{Discussion and Conclusions}

The main intent of the current study was to investigate the effectiveness of Blackboard in developing integrated English-language skills. Results of the study proved the effectiveness of the proposed model as well as the suggested strategy. Blackboard proved to be characteristically equipped with facilities that help integrate reading and writing in the foreign language, such as blogs, 
synchronous chats, asynchronous discussion boards and wikis. In this way, it was more than suitable for integrated English-language instruction. The integrated-skills strategy proved to be so much beneficial as contrasted with the purely segregated approach traditionally adopted in our classrooms. The strategy proved to be effective, in the first instance, because the skills it attempted to develop are integrated in real life. E-learning environment, via Blackboard, highlighted the significant role of socio-communicative interaction among students and with the teacher. It established an online community in which active participants got an interactive audience to read their material. It provided proper conditions for receiving scaffolding from the course tutor and constructive feedback from peers. Students had an access to revise, edit and make additions and improvements on their own and others' writings. In one word, Blackboard helped personalize teaching/learning tasks. It played an important role in developing various dimensions of student autonomy: strategy use, self-learning awareness, behavioural and social interdependence, ... etc. It minimized boredom and monotony to the barest minimum. It gave absent students a chance to rehearse their missed classes. Moreover, Blackboard is usually user-friendly. It is also environment-friendly, since there is no longer any need for waste paper.

Blackboard tools were used in the current study both synchronously and asynchronously. They provided private space to make mistakes and enhance students' confidence. One of the advantages emphasized by students was its offering useful feedback. Moreover, Blackboard offered various options for various students' choices, such as emails, chats, instant messaging, SMS, discussion boards, feedback on students' assignments, journals, wikis and collaborative projects. Students made good use of Blackboard's advantages of providing easy access to authentic online materials and supporting self-based learning. In addition, Blackboard helped make the teaching/learning experience more lively. It allowed the students to interact with each other and with the teacher anywhere at any time. It helped build teacher-student rapport. In this respect, the researcher would like to elucidate that Blackboard's motivational feature was high. It allowed a considerable amount of peer and group learning. There were no time constraints to access the materials. Moreover, recorded sessions helped the students cover up the missed classes. In this manner, it enhanced student autonomy. Furthermore, Blackboard helped integrate and provide easy access and usability of the instructional management feature. The key interaction support features included discussion boards, course reports, grade centre, groups, assignment and form assessments, on/off editing mode, course management, tests/surveys/pools and drag/drop features. Blackboard increased accessibility and availability. It gave momentum to synchronous and asynchronous communication. It maintained verbal and non-verbal communication and enhanced collaborative and interactive learning environment via addressing different learning styles, alleviating performance anxiety and ensuring equality of participation.

Blackboard-based instruction employed tools for collaboration and interaction which are important aspects of effective learning environment. It employed different multi-sensory tools that appealed to the participants' various learning styles and multiple intelligences. In this way, Blackboard provided the participants with various techniques of feedback. Furthermore, it created a scaffolding learning environment. Blackboard-based instruction made learning less daunting and helped with revision before tests. As many EFL learners suffer from performance anxiety in face-to-face communication, Blackboard-based instruction helped the participants alleviate their performance anxiety. It provided the participants with more learning varieties, including live interactive virtual classes, emails (course messages) and electronic discussion groups (chat rooms), bulletin boards (course announcements), downloadable recorded course materials or tutorials, interactive tutorials on the web and informatics.

It may be quite apt in this connection to shed some light on a few problems the researcher came upon in the mainstream of using Blackboard; most of them have to do with lack of benefits of face-toface interaction, loss of habitual academic classroom atmosphere and technical inconveniencies that may hamper proceedings of the session. 


\section{Recommendations and Suggestions for Further Research}

In light of the main results of the current study, the researcher recommends that:

1-Special training courses should be held for students to enable them to make use of L.M.Ss in their learning practices. Blackboard - one of these systems - proved to be effective in the present study.

2-Proper theoretical background should be presented to teachers as well as students about the use of such systems beforehand. Manuals and leaflets should be available for those who are novice users.

3-Teachers should be thoroughly trained in using L.M.Ss for educational and administrative purposes.

4-Teachers as well as students should be trained in how to deal with English-language skills in an integrative way.

5-Technical and logistic support should be offered in order to surmount problems students and teachers might encounter while using Blackboard.
6-Following the same footsteps of the current study, the researcher thinks that more studies are needed to:

-Explore the effect of Blackboard on developing other language skills; namely, listening and speaking.

-Examine teachers' and students' attitudes towards using L.M.Ss in the teaching/learning process.

-Replicate the proposed model and the suggested strategy for other educational stages.

-Further investigate the difference between males and females in (integrated English-language skills).

-Design similar models using different kinds of L.M.Ss.

-Further investigate the effectiveness of the integrative approach in developing other language skills.

-Develop training programmes that help students overcome psychological barriers associated with internet usage

\section{References}

Al-Dosari, H., \& Mekheimer, M. (2013). The bandwagon effect in the adoption of e-learning systems in language learning: An Appraisal. GSTF Journal on Computing, 2(4), 61-81.

Al-Harbi, M. (2015). Effects of Blackboard's discussion boards, blogs and wikis on effective integration and development of literacy skills in EFL students. EnglishLanguage Teaching, 8(6), 111-132.

Al-Hassan, S. and Shukri, N. (2017). The effect of blended learning on enhancing female students' satisfaction in the Saudi context. English-Language Teaching, 10(6), 190-203.

Ali, R. (2017). Non-English major university students' perceptions of Blackboard as a learning-management system (LMS) in learning basic english grammar. International Journal of Recent Scientific Research, 8(11), 21649-21652.
Al-Malki, M. \& Soomro, A. (2017). Practitioners' perspectives on the application of integration theory in the Saudi EFL context. EnglishLanguage Teaching, 10(6), 93-102.

Al-Omrani, A. (2014). Integrating reading into writing instruction in the EFL programmes at Saudi universities. AWEJ, 5(3), 100-112.

Al-Saghir, L. and Wazen, W. (2020). A Competency-based education approach for effective on-line programme design: Exploring e-learning platforms' compatibility. International Journal on E-Learning, 19(1), 523.

Al-Turki, U., Al-Draiweesh, A., \& Athabaska, K. (2016). Evaluating the usability and accessibility of LMS "Blackboard" at King Saud University. Contemporary Issues in Education Research - First Quarter, 9(1), 3344. 
Bouhnik, D., \& Marcus, T. (2006). Interaction in distance-learning courses. Journal of the American Society of Information Science and Technology, 57(3), 299-305.

Chen, J.; Dobinson, T., \& Kent, S. (2019). Students' perspectives on the impact of Blackboard Collaborate on Open University Australia (OUP) online learning. Journal of Education Online, 1,1-12.

Cooney, A., Darcy, E., \& Casey, D. (2018). Integrating reading and writing: Supporting students' writing from source. Journal of University Teaching and Learning Practice, 15(5), 1-18.

El-Feky, A., \& Masadeh, T. (2016). The effect of mobile learning on students' achievement and conversational skills. International Journal of Higher Education, 5(3), 20-31.

El-Ghamry, H. (2016). The effect of Blackboard Collaborate-based instruction on pre-service teachers' achievement in the EFL teaching methods course at Faculties of Education for Girls. English-Language Teaching, 9(3), 4967.

Evans, M. (2018). The integration of reading, writing, speaking, and listening skills in the middle school social studies classroom. ProQuest LLC, Ph.D. Dissertation, Utah State University.

Hamad, M. (2017). Using WhatsApp to enhance students' learning of English language "experience to share". Higher-Education Studies,7(4), 74-87.

McArthur, D. (2014). Integrating reading and writing for Florida's ESOL programme (Unpublished M.A. Thesis). University of South Florida.
Milad, M. (2017). Blended-learning approach: Integrating reading and writing research skills to improve academic writing. Arab Journal of Applied Linguistics, 3(3), 23-55.

Mohsen, M., \& Shafeeq, P. (2014). EFL teachers' perceptions on Blackboard applications. English-Language Teaching, 7(11), 108-118.

Niyibizi, E., Sibomana, E., \& Perumal, J. (2019). Learning to teach writing through a distanceeducation programme: Experiences of Rwandan secondary-school English teachers. Reading and Writing, 10(1), 2-10.

Pysarchyk, L. \& Yamshynska, V. (2015). The importance of integrating reading and writing for the EFL Teaching. Advanced Education, 3, 77-83.

Tawalbeh, T. (2018). EFL instructors' perceptions of Blackboard learning-management system (LMS) at University level. English-Language Teaching, 11(1), 1-9.

Tella, A. (2011). Reliability and factor analysis of a Blackboard course-management system Success: A scale development and validation in an educational context. Journal of Information-Technology Education, 10(1), 5580.

Tsai, Y. (2015). Applying the technologyacceptance model (TAM) to explore the effects of a course-management system (CMS)-assisted EFL writing instruction. CALICO, 32(1), 153-171.

Wong, Y. (2018). Exploring the reading-writing relationship in young chinese language learners' sentence writing. Reading and Writing: An Interdisciplinary Journal, 31(4), 945-964. 